\title{
PENANAMAN PENDIDIKAN KARAKTER DI SEKOLAH DI KABUPATEN WAKATOBI
}

\author{
${ }^{1}$ Felta, ${ }^{2}$ Nursin, ${ }^{3}$ Darwis Buton, ${ }^{4}$ Joleha Nacikit, ${ }^{5}$ Eka Wati Belen, ${ }^{6}$ Noni Siompo \\ ${ }^{1}$ Universitas Haluoleo \\ ${ }^{23456}$ Universitas Iqra Buru
}

\begin{abstract}
Abstrak
Tujuan penelitian ini adalah mengidentifikasi upaya penerapan pendidikan karakter di SDN 1 Ambeua Kabupaten Wakatobi. Jenis penelitian ini merupakan penelitian deskriptif kualitatif. Data yang diperoleh merupakan data primer dan data sekunder. Metode dalam penelitian ini adalah metode observasi dengan teknik pengumpulan data yang digunakan, yakni observasi non partisipatif, wawancara mendalam, studi dokumentasi, studi literatur. Teknik analisis data yang digunakan, yakni reduksi data, penyajian data, dan penarikan kesimpulan.

Hasil penelitian membuktikan bahwa Ada lima upaya penerapan pendidikan karakter yang telah diterapkan oleh pihak SD Negeri 1 Ambeua yang dapat dilihat secara materil dan non materil, yakni 1) penanaman karakter yang religious, yakni sikap dan perilaku yang patuh dalam melaksanakan ajaran agama yang dianutnya, toleran terhadap pelaksanaan ibadah agama lain, dan hidup rukun dengan pemeluk agama lain; 2) penumbuhan karakter nasionalis seperti selalu mengikuti upacara bendera, menghafal butir-butir pancasila dan Undang-Undang Dasar 1945, taat kepada peraturan sekolah, dan lain-lain; 3) penanaman karakter yang integritas, yakni Sikap yang teguh mempertahankan prinsip, tidak mau korupsi, dan menjadi dasar yang melekat pada diri sendiri sebagai nilai-nilai moral; 4) penumbuhan karakter mandiri, yakni sikap seseorang yang tidak selalu bergantung pada orang lain, dan selalu melakukan sesuatu secara sendiri tanpa arahan atau bergantungan dengan orang lain; 5) membiasakan hidup bergotong royong seperti saling menolong jika ada teman yang mengalami kesusahan.
\end{abstract}

Kata kunci: penerapan, pendidikan, karakter, sekolah, wakatobi.

\begin{abstract}
The purpose of this study was to identify efforts to implement character education in SDN 1 Ambeua Wakatobi Regency. This type of research is a qualitative descriptive study. The data obtained are primary data and secondary data. The method in this research is an observation method with data collection techniques used, namely nonparticipatory observation, in-depth interviews, documentation study, literature study. The data analysis techniques used were data reduction, data presentation, and conclusion drawing.

The results of the research prove that there are five efforts to implement character education that have been implemented by SD Negeri 1 Ambeua which can be seen materially and non-materially, namely 1) the inculcation of religious character, namely obedient attitudes and behavior in implementing religious teachings. towards the practice of worship of other religions, and living in harmony with adherents of other religions; 2) the development of a nationalist character such as always following flag ceremonies, memorizing Pancasila points and the 1945 Constitution, obeying school regulations, and so on; 3) instilling a character of integrity, namely an attitude that is firm in maintaining principles, does not want to be corrupt, and becomes a basis that sticks to oneself as moral values; 4) the development of independent character, namely the attitude of a person who is not always dependent on others, and always does something independently without direction or depending on other people; 5) getting used to living together like helping each other if a friend is experiencing difficulties.
\end{abstract}

Keyword: application, education, character, school, wakatobi 


\section{PENDAHULUAN}

Dalam dunia pendidikan karakter sangat dibutuhkan peserta didik untuk membentuk pribadi yang baik, bijaksana, jujur, bertanggung jawab dan bisa menghormati orang lain. Karakter adalah watak atau sifat, akhlak ataupun kepribadian yang membedakan seorang individu dengan individu lainnya. Karakter dapat dikatakan sebagai keadaan sebenarnya dari dalam diri seorang individu yang membedakan antara dirinya dengan individu lain. Menurut Krismanto dalam Taufik dan Susiati (2019) masyarakatakan cenderung lebih cepat mengalami, mengantisipasi dan menyesuaikan dengan berbagai perubahan dan kemajuan ketika individu-individu yang ada dalam masyarakat itu memiliki kemampuan dan budaya membacayang tinggi.

Muslich dalam Susiati dan Taufik (2019) menyatakan bahwa karakter adalah cara berfikir dan berperilaku seseorang yang menjadi ciri khas dari tiap individu untuk hidup dan bekerja sama baik dalam keluarga, masyarakat, dan negara. Susiati, et.al (2019), improving the quality of education is one of the most important elements in efforts to improve the quality of human resources, especially in the effectiveness og the teaching and learning process. Bentuk kegiatan manusia yang didalamnya terdapat suatu tindakan yang mendidik diperuntukkan bagi generasi selanjutnya. Pendidikan karakter adalah untuk membentuk penyempurnaan diri individu secara terus menerus dan melatih kemampuan diri demi menuju kearah hidup yang lebih baik. Siapa yang harus melakukan pendidikan karakter?

Pemerintah telah menerbitkan Perpres tentang Penguatan Pendidikan Karakter (PPK). PPK merupakan kebijakan pendidikan yang tujuan utamanya adalah untuk mengimplementasikan Nawacita Presiden Joko Widodo-Jusuf Kalla dalam sistem pendidikan nasional. Kebijakan PPK ini terintegrasi dalam Gerakan Nasional Revolusi Mental (GNRM), yaitu perubahan cara berpikir, bersikap, dan bertindak menjadi lebih baik (Susiati, 2020).

Nilai-nilai utama PPK adalah religius, nasionalis, mandiri, gotong royong, integritas. Nilai-nilai ini ingin ditanamkan dan dipraktikkan melalui sistem pendidikan nasional agar diketahui, dipahami, dan diterapkan di seluruh sendi kehidupan di sekolah dan masyarakat (Susiati, 2020). PPK lahir karena kesadaran akan tantangan ke depan yang semakin kompleks dan tidak pasti, namun sekaligus melihat ada banyak harapan bagi masa depan bangsa. Hal ini menuntut lembaga pendidikan untuk mempersiapkan peserta didik secara keilmuan dan kepribadian, berupa individu-individu yang kokoh dalam nilai-nilai moral, spiritual dan keilmuan. 
Pendidikan karakter adalah program pendidikan nasional di Indonesia terutama di Kabinet Pembangunan Indonesia Bersatu II. Pembentukan karakter peserta didik tergantung pada aspek penekanannya diantaranya yang umum dikenal adalah pendidikan moral, pendidikan nilai, pendidikan relegius, pendidikan budi pekerti dan pendidikan karakter.

Disadari bahwa pendidikan karakter perlu mendapat perhatian dari semua pihak. Di sekolah siswa perlu mendapatkan pembinaan karakter yang baik, orang tua dan orang dewasa perlu memberikan keteladanan yang pantas ditiru oleh anak.

Pendidikan karakter sangat penting sekali. Pembentukan karakter akan menentukan bagaimana orang itu menjalani hidup. Karakter ada yang positif dan ada yang negatif. Penanaman karakter positif sangat diperlukan. Mulai kecil anak harus dibimbing diajari untuk mempunyai karakter yang positif. Supaya menjadi modal anak itu untuk menjalani kehidupan di masa yang akan datang. Anak harus mempunyai karakter yang kuat, berani dan tidak mudah menyerah.

Karakter positif harus selalu diterapkan dimanapun kita berada. Sebab, manusia yang tidak mempunyai karakter positif, akan menimbulkan masalah dan tidak bisa mendapatkan solusi dari sebuah masalah. Pendidikan karakter anak jadi kurang. Namun dalam pembentukan karakter pertama adalah orang tua. Pendidikan karakter yang paling banyak pengaruhnya adalah pengajaran dari orang tua. Anak hanya menerima dan tidak bisa menolak segala ilmu yang diberikan ketika balita dan kasih sayang orang tua yang paling berperan dalam menemukan karakter anak supaya tidak terjerumus hal-hal yang negatif.

Kurniati et.al (2020) menyatakan bahwa saat ini upaya pengembangan pembelajaran, tujuan pendidikan, dan penilaian di Sekolah Dasar (SD) belum tercapai dengan maksimal. Hal ini terjadi karena dalam proses kegiatan belajar mengajar masih ditemukan ketidaksesuaian antara tujuan pendidikan yang mengacu pada character dan nation building. Untuk dapat mencapai pada pengembangan character dan nation building semestinya pembinaan dan penanama karakter harus dikembangkan dan dimasukkan dalam setiap materi pembelajaraan.

Pengupayaan

pengembangan pendidikan karakter yang selama ini sudah dimasukkan dalam kurikulum tidak sepenuhnya terlaksana dengan baik dan tepat. Kondisi lingkungan, budaya, dan karakter masyarakat, dan karakter para siswa menjadikan pengembangan pendidikan karakter perlu diterapkan sesuai dengan kondisi lingkungan dan kebutuhan yang diinginkan oleh setiap anak. Segala macam upaya telah dilakukan oleh pihak SD Negeri 1 Ambeua, tetapi tidak sedikit upaya tersebut terhambat oleh ketidakcocokan media penghantar pendidikan karakter dengan keinginan para siswa.

$$
\text { Adakalanya orang-orang di }
$$
lingkungannya banyak yang berkarakter negatif, anak bisa terbawa lingkungan tersebut. Oleh karena itu pendidikan 
karakter tidak hanya diperlukan di sekolah saja tetapi juga di lingkungan keluarga.

Berdasarkan latarbelakang di atas, maka tujuan penelitian ini adalah mengidentifikasi penerapan pendidikan karakter di Sekolah Dasar Negeri 1 Ambeua.

\section{LANDASAN TEORI}

\section{Pendidikan Karakter}

Pendidikan karakter merupakan bentuk kegiatan manusia yang di dalamnya terdapat suatu tindakan yang mendidik diperuntukkan bagi generasi selanjutnya. Tujuan pendidikan karakter adalah untuk membentuk penyempurnaan diri individu secara terus-menerus dan melatih kemampuan diri demi menuju kearah hidup yang lebih baik.

Pendidikan karakter dapat dikatakan sebagai usaha manusia secara sadar dan terencana dalam hal mendidik sekaligus memberdayakan peserta didik dengan tujuan membangun karakter pribadi peserta didik. Tentu saja hal ini dilakukan agar nantinya peserta didik menjadi individu yang bermanfaat bagi diri sendiri dan orang banyak. Menurut John W. Santrock, pendidikan karakter merupakan pendidikan dengan pendekatan langsung pada peserta didik dengan tujuan menanamkan nilai moral sehingga dapat mencegah perilaku yang dilarang.

Pendidikan karakter berhubungan erat dengan psikis individu. Dengan pendidikan karakter, dapat diajarkan pandangan tentang nilai-nilai kehidupan, contohnya kejujuran, kepedulian, tanggung jawab, hingga keimanan.

\section{Fungsi Pendidikan Karakter}

Fungsi pendidikan karakter, di antaranya:

a. Mengembangkan potensi dasar manusia agar menjadi individu yang berhati, berpikiran, dan berperilaku baik.

b. Membangun dan memperkuat perilaku masyarakat, dalam hal ini masyarakat Indonesia yang multikultural.

c. Membangun dan meningkatkan peradaban bangsa.

Dengan fungsi penting yang dimilikinya, Quipperian pasti setuju kalau pendidikan karakter ini harus dilakukan sedini mungkin. Di Indonesia sendiri, dalam nawacita, disebutkan bahwa pemerintah akan melakukan revolusi karakter bangsa. Karenanya, Kementrian Pendidikan dan Kebudayaan (Kemendikbud) menggalakkan gerakan Penguatan Pendidikan Karakter (PPK) sejak 2016 silam. Pendidikan karakter dalam jenjang pendidikan dasar lebih besar porsinya dibandingkan jenjang pendidikan yang mengajarkan pengetahuan. Tepatnya, $70 \%$ untuk sekolah dasar dan 60\% untuk sekolah menengah pertama.

PPK sendiri tidak mengubah struktur kurikulum di Indonesia. Dalam penerapannya, hanya dilakukan sedikit modifikasi intrakurikuler yang ditambahkan dengan kegiatan kokurikuler dan esktrakurikuler. PPK diharapkan dapat menumbuhkan budi pekerti dan menguatkan karakter positif anak didik. PPK 
mendorong adanya sinergi di antara tiga pusat pendidikan, yaitu sekolah, keluarga, dan komunitas.

\section{METODE PENELITIAN}

Jenis Penelitian

Jenis penelitian yang digunakan dalam penelitian ini adalah deskriptif kualitatif (The method used is descriptive qualitative) (Nadir, et.al, 2019). Penelitian deskriptif merupakan penelitian dengan mengumpulkan data untuk mengetes pertanyaan penelitian atau hipotesis yang berkaitan dengan keadaan dan kejadian sekarang, melaporkan keadaan objek atau subjek yang diteliti sesuai apa adanya (lye, et.al, 2020). Penelitian ini mengkaji suatu upaya pelaksanaan dan pengembangan pendiddikan karakter di SD Negeri 1 Ambeua, Kecamatan Kaledupa, Kabupaten Wakatobi.

\section{Data dan Sumber Data}

Data dalam penelitian ini diperoleh melalui data primer dan data sekunder. Data primer berupa data yang diperoleh langsung dari sumber aslinya, yaitu dengan menggunakan teknik observasi dan wawancara mendalam. Data sekunder ialah data yang berasal dari dokumen di kantor.

Sumber data penelitian ini diperoleh dari beberapa informan dengan menerapkan criterion based selection, yakni subjek bertindak sebagai aktor dalam tema penelitian. Penentuan informan menggunakan model snowball. Penelitian ini mengambil informan kunci kepala. Selanjutnya, data yang diperoleh dari informan kunci ditriangulasi dengan data dari informan tambahan, yang berasal dari guru kelas I-VI, wali kelas, guru agama, guru seni, guru penjaskes, dan siswa SD Negeri 1 Ambeua. Moleong (2007) menyatakan bahwa triangulasi digunakan sebagai teknik untuk mengecek keabsahan data (hal. 42).

\section{Metode dan Teknik Pengumpulan Data}

Metode pengumpulan data yang digunakan dalam penelitian ini adalah observasi. Observasi digunakan untuk memperhatikan secara akurat suatu kegiatan, memperhatikan relasi antara aspek dalam situasi yang terjadi, mencatat fenomena yang muncul, dan mengamati objek kajian dalam konteks atau situasi.

Penggunaan metode observasi dilakukan untuk mendapatkan data lisan dan tertulis berupa upaya pengembangan pendidikan karakter di SD Negeri 1 Ambeua. Untuk menunjang penggunaan metode observasi peneliti menggunakan teknikteknik pengumpulan data secara observasi non partisipatif, wawancara mendalam, studi dokumentasi, studi literatur.

\section{Penganalisisan Data}

Untuk menganalisis data yang diperoleh, peneliti menggunakan langkahlangkah penganalisisan data sebagai berikut.

1. Perediksian data (data reduction)

Pereduksian data adalah proses pemusatan perhatian pada penyederhanaan, pemilihan data, pengabstrakan, dan pentransformasian data "kasar" dari catatan di lapangan.

2. Penyajian data (data display) 
Penyajian data dilakukan dengan menyusun berbagai informasi yang berasal dari penarikan kesimpulan dan pengambilan tindakan.

3. Penarikan kesimpulan (data verification)

Dari hasil penyajian data maka akan dilakukan suatu penarikan kesimpulan yang di dalamnya berupa makna dari data yang dikumpulkan (Susiati, 2018).

\section{HASIL PENELITIAN}

\section{Pendidikan Karakter di Sekolah Dasar Negeri 1 Ambeua}

Sesuai dengan dasar negara kita, Pancasila, ada lima karakter utama yang merupakan fokus pengembangan yang dilaksanakan oleh para tenaga pendidik di Sekolah Dasar Negeri 1 Ambeua, yaitu

1. Religius

Karakter pertama yang berhubungan dengan iman kepada Tuhan yang Maha Esa ini diwujudkan dalam pelaksanaan ajaran agama dan kepercayaan yang dianut, menghargai perbedaan agama, menjunjung tinggi toleransi terhadap pelaksanaan ajaran agama dan kepercayaan yang berbeda, juga hidup rukun dan damai dengan pemeluk agama lain.

Jika kamu memiliki sikap anti perundungan, mencintai kedamaian, melindungi yang tersisih, menghargai perbedaan agama dan kepercayaan, membuka diri pada persahabatan, tidak memaksakan kehendak, dan tentu saja, toleransi, berarti karakter religius tertanam dengan baik dalam dirimu.
Bagaimana teori karakter religius diberikan di sekolah khususnya di SDN 1 Ambeua? Yang utama adalah pada saat kegiatan belajar mengajar mata pelajaran Pendidikan Agama Islam (PAI). Bagaimana praktik karakter religius di sekolah, yaitu dengan model pembiasaan, bisa harian atau mingguan. Contoh pembiasaan harian, yaitu 3S (Senyum, Sapa, Salam), pembacaan doa sebelum belajar dan sesudah belajar, serta para siswa maju di depan kelas untuk membaca salah satu surah dalam Alqur'qan. Sebagai pendukungnya adalah kegiatan ekstrakurikuler yang berkarakter religius seperti: Qiro'ah, Adzan, dan rebana.

Sikap dan tindakan yang mencerminkan karakter religius terhadap siswa di SDN 1 Ambeua seperti berikut siswa bersyukur terhadap hasil ulangannya, menjenguk temannya yang sakit, menolong temannya yang kena musibah. Sehingga terlaksana seimbang antara religius ibadah dengan religius sosial. Yang terpenting adalah menjadikan karakter religius ini membudaya di kalangan siswa siswi baik di lingkungan sekolah maupun masyarakat. Kita sebagai pendidik sekaligus orang tua harus selalu sabar dan semangat dalam menanamkan nilai karakter religius ini.

Guru selalu mengingatkan para siswa tentang anjuran dan larangan, menceritakan kisah-kisah inspiratif dari tokoh agama dan menciptkan suasana ibadah yang menyenangkan di lingkungan sekolah. Jika karakter religius ini sudah terbentuk dengan kuat maka penulis yakin bahwa nilai karakter yang lain pun akan mengikuti. 


\section{Nasionalis}

Karakter kedua menggarisbawahi bahwa kepentingan bangsa dan negara adalah di atas kepentingan diri dan kelompok semata. Untuk memperoleh pemahaman tersebut, yang harus menjadi perhatian adalah cara berpikir dan bersikap, serta kepedulian.

Seseorang dengan karakter nasionalis akan mengapresiasi kebudayaan bangsanya, kemudian menjaga dan menghormati kekayaan budaya tersebut. Di Indonesia yang beragam budaya, suku, dan agama, karakter ini begitu penting karena mampu menjadikanmu rela berkorban, disiplin, dan taat hukum.

Kemajuan teknologi informasi dan komunikasi yang menjadi ciri dari era industri yang sudah generasi 4.0 atau Jepang dengan visinya Society 5.0 turut berkontribusi terhadap perubahan global ini.

Tentunya, orangtua sebagai guru di rumah dalam menanam nilai karakter nasionalis perlu dikontekstualisasikan dengan kondisi ini. Dalam buku Konsep dan Pedoman PPK bagi anak sekolah tingkat dasar, penanaman nilai karakter nasionalis memiliki beberapa subnilainya yang begitu luas untuk penerapannya, yaitu apresiasi budaya bangsa sendiri, menjaga kekayaan budaya bangsa, rela berkorban, unggul, dan berprestasi, cinta tanah air, menjaga lingkungan, taat hukum, disiplin, menghormati keragaman budaya, suku, dan agama.

Intinya, penanaman nilai karakter nasionalis harus mampu meningkatkan semangat kesetiaan dan cinta terhadap bangsa dan negara pada anak kita. Bentuk penanaman karakter nasionalis pada SDN 1 Ambeua, yakni ketika anak mendapatkan pelajaran dari guru sekolah tentang mata pelajaran tema 9 membahas "Kayanya Negeriku" dengan subtema 1 membahas "Kekayaan Sumber Energi di Indonesia," maka ini dapat dijadikan pintu masuk bagi tenaga pendidik dan orangtua untuk menanamkan nilai karakter nasionalis dan dikaitkan juga nilai karakter lainnya seperti nilai karakter religius yang telah dibahas pada artikel kedua.

Pelajaran subtema mengenal sumbersumber energi menjadi pusat untuk dikaitkan dengan muatan pada mata pelajaran lainnya seperti Bahasa Indonesia dan Pendidikan Pancasila dan Kewarganegaraan (PPKn). Tugas pelajaran Bahasa Indonesia yang diberikan guru dengan membuat daftar pertanyaan dan jawaban menggunakan kata tanya apa, berapa, siapa, di mana, kapan, mengapa, dan bagaimana terkait sumber energi. Sedangkan dalam pelajaran PPKn, tugasnya adalah dengan mengidentifikasi manfaat dan kewajiban yang harus dilakukan terhadap sumber energi yang sifatnya terbatas yang dimiliki Indonesia.

Orangtua dan guru sebagai fasilitator yang memandu anak untuk melakukan penemuan (discovery) sendiri solusinya dengan menggunakan sumber berlajar yang ada di sekitar rumah. Jika anak sudah berhasil melakukan penemuan ide atau solusinya dan membangun kesimpulannya, maka orangtua dapat memberikan penguatan atas idenya dan tidak lupa 
dengan penanaman nilai karakter nasionalis dan karakter lainnya. Lebih baik lagi, untuk pelajaran tema tersebut selalu dikaitkan juga dengan kondisi pandemi Covid-19 saat ini, dimana semua kegiatan banyak dilakukan di rumah dan berdampak pada meningkatnya kebutuhan energi, maka menjadi semakin relevan pembahasan pelajaran ini.

Dengan demikian, dari satu contoh pelajaran yang membahas tema "Kayanya Negeriku" dengan subtema "Kekayaan Sumber Energi di Indonesia," para guru dan orangtua di samping membimbing anak untuk meningkatkan aspek pemahaman dan tidak lupa juga memberikan penanaman nilai karakter untuk membangun sikap dan perilaku anak dalam meningkatkan nilai karakter nasionalis yang ada dalam dirinya. Silakan orangtua mencoba pada tema dan pelajaran lainnya.

\section{Integritas}

Karakter ketiga ini adalah nilai yang berdasar pada usaha seseorang memperbaiki dirinya agar dapat menjadi orang yang dapat dipercaya dalam perkataan, tindakan, dan pekerjaannya. Di samping itu, seseorang dengan karakter ini juga memiliki komitmen serta kesetiaan terhadap nilai-nilai kemanusiaan dan juga moral.

Kamu dapat menunjukkan karakter integritas dalam dirimu dengan cara menunjukkan tanggung jawab sebagai warga negara, aktif terlibat kegiatan sosial, menghargai martabat orang lain, dan menunjukkan keteladanan.

\section{Mandiri}

Karakter keempat menunjukkan sikap tidak bergantung pada orang lain. Ketidaktergantungan ini dimaksudkan dalam mengarahkan tenaga, pikiran, dan waktu sendiri demi mewujudkan cita-cita.

Jika kamu memiliki karakter mandiri, berarti kamu memiliki etos kerja yang baik, ketangguhan, daya juang, profesionalitas, kreativitas, dan keberanian. Wih!

\section{Gotong royong}

Karakter terakhir terlihat dari sikap menghargai semangat kerja sama dan bahu membahu dalam menyelesaikan masalah bersama, menjalin komunikasi dan persahabatan, serta memberi pertolongan bagi orang yang membutuhkan.

\section{PENUTUP}

Berdasarkan pembahasan sebelumnya terkait penerapan pendidikan karakter pada SDN 1 Ambeua, maka hasil penelitian membuktikan bahwa Ada lima upaya penerapan pendidikan karakter yang telah diterapkan oleh pihak SD Negeri 1 Ambeua yang dapat dilihat secara materil dan non materil, yakni 1) penanaman karakter yang religious, yakni sikap dan perilaku yang patuh dalam melaksanakan ajaran agama yang dianutnya, toleran terhadap pelaksanaan ibadah agama lain, dan hidup rukun dengan pemeluk agama lain; 2) penumbuhan karakter nasionalis seperti selalu mengikuti upacara bendera, menghafal butir-butir pancasila dan UndangUndang Dasar 1945, taat kepada peraturan sekolah, dan lain-lain; 3) penanaman 
karakter yang integritas, yakni Sikap yang teguh mempertahankan prinsip, tidak mau korupsi, dan menjadi dasar yang melekat pada diri sendiri sebagai nilai-nilai moral; 4) penumbuhan karakter mandiri, yakni sikap seseorang yang tidak selalu bergantung pada orang lain, dan selalu melakukan sesuatu secara sendiri tanpa arahan atau bergantungan dengan orang lain; 5) membiasakan hidup bergotong royong seperti saling menolong jika ada teman yang mengalami kesusahan.

\section{DAFTAR PUSTAKA}

Amanto, B. S., Umanailo, M. C. B., Wulandari, R. S., Taufik, T., \& Susiati, S. (2019). Local Consumption Diversification. Int. J. Sci. Technol. Res, 8(8), 1865-1869.

Iye, R., \& Susiati, S. (2018). NILAI EDUKATIF DALAM NOVEL SEBAIT CINTA DI BAWAH LANGIT KAIRO KARYA MAHMUD JAUHARI ALI (Educative Values in Sebait Cinta di Bawah Langit Kairo by Mahmud Jauhari Ali). Sirok Bastra, 6(2), 185-191.

Susiati, S., \& lye, R. (2018). Kajian Geografi Bahasa dan Dialek di Sulawesi Tenggara: Analisis Dialektometri. Gramatika: Jurnal Ilmiah Kebahasaan dan Kesastraan, 6(2), 137-151.

Tuasalamony, Kurniati; Hatuwe, Rahma Satya Masna; Susiati, Susiati; Masniati, Andi; Marasabessy, Roos Nilawati. (2020). PENGEMBANGAN PENDIDIKAN KARAKTER DI SEKOLAH DASAR NEGERI 5 NAMLEA. Pedagogy. 7(2), 81-91.

Susiati, S., Iye, R., \& Suherman, L. O. A. (2019). Hot Potatoes Multimedia Applications in Evaluation of Indonesian Learning In SMP Students in Buru District. ELS Journal on Interdisciplinary Studies in Humanities, 2(4), 556-570.

Susiati, S. (2018). Homonim bahasa kepulauan tukang besi dialek kaledupa di kabupaten wakatobi [the homonymon of tukang besi island languange in kaledupa dialect at wakatobi regency]. Totobuang, 6 (1), 109, 123.

Iye, R., Susiati, S., \& Karim, K. (2020). Citra Perempuan dalam Iklan Sabun Shinzui. Sang Pencerah:
Jurnal Ilmiah Universitas Muhammadiyah Buton, 6(1), 1-7.

Susiati, S. (2020). Semantik: Teori Semantik, Relasi Makna, Marked, Dan Unmarked.

Susiati, S. (2020). Bahan Ajar: Psikolinguistik.

Lafamane, F. (2020). Perkembangan Teori Sastra (suatu Pengantar).

Nafinuddin, S. (2020). Analisis Kesalahan Berbahasa Dalam Bahasa Indonesia.

Lafamane, F. (2020). Metode Pembelajaran (Pendapat Para Ahli).

Lafamane, F. (2020). Tata Bahasa Sistemik Fungsional (Suatu Pandangan).

Susiati, S. (2020). Konsep Keterasingan Dalam Film" Aisyah Biarkan Kami Bersaudara" Karya Herwin Novianto.

Susiati, S. (2020). Concept Of Conflict In The Films "AISYAH BIARKAN KAMI BERSAUDARA" By Herwin Novianto.

Djamudi, N. L., Nurlaela, M., Nazar, A., Nuryadin, C., Musywirah, I., \& Sari, H. (2019, October). Alternative social environment policy through educational values in Kafi'a's customary speech to the kaledupa community of Wakatobi Island, Indonesia. In IOP Conference Series: Earth and Environmental Science (Vol. 343, No. 1, p. 012118). IOP Publishing.

Iye, R., Tenriawali, A. Y., Susiati, A., \& Buton, D. (2020). Makna dan Fungsi Emosi Mahasiswa Kota Baubau dalam Ranah Demonstrasi: The Meaning And Emotional Function Of Students Of Baubau City In The Demonstration Plan. Uniqbu Journal of Social Sciences, 1(1), 25-37.

Susiati, S., \& lye, R. (2018). Kajian Geografi Bahasa dan Dialek di Sulawesi Tenggara: Analisis Dialektometri. Gramatika: Jurnal IImiah Kebahasaan dan Kesastraan. 6 (2), 137-151.

Taufik, T. (2019). Strategi AMBT untuk Meningkatkan Kemampuan Membaca Pemahaman Interpretatif Siswa Kelas IV SD Negeri 3 Namlea Kabupaten Buru. Sang Pencerah: Jurnal IImiah Universitas Muhammadiyah Buton, 5(2), 5362.

Susiati, Y. T. Risman lye. A. Kesantunan Imperatif Bahasa Indonesia Suku Bajo Sampela: Balai Pembinaan dan Pengembangan Bahasa. 2018. Kongres Bahasa Indonesia (No. 12, pp. 1-6). Report.

Susiati, S. (2020). Kaidah Fonologi Bahasa Indonesia.

Susiati, S. (2020). Pengaplikasian Multimedia Hot Potatoes Dalam Evaluasi Pembelajaran Bahasa Indonesia Pada Siswa SMP Negeri 9 Buru. 
Susiati, S. (2020, June 27). Nilai Pembentuk Karakter Masyarakat Wakatobi Melalui Kabhanti Wa Leja. https://doi.org/10.26499/ttbng.v7i1.136

Musyawir, M., \& Loilatu, S. H. . (2020). KEMAMPUAN MENULIS KARANGAN NARASI BERDASARKAN PENGALAMAN PRIBADI SISWA: (The Ability to Write a Narrative Essay Based on Students' Personal Experiences). Uniqbu Journal of Social Sciences, 1(2), 1-12. https://doi.org/10.47323/ujss.v1i2.20

farid, M. (2020). 'DOKTER JAWA' DI PENGASINGAN BANDA: TELADAN NASIONALISME DAN HUMANISME TJIPTO MANGUNKUSUMO DI BANDA NAIRA: ('Dokter Jawa' in Exile of Banda: The Model of Nationalism and Humanism Tjipto Mangunkusumo in Banda Naira). Uniqbu Journal of Social Sciences, 1(2), 13-21. https://doi.org/10.47323/ujss.v1i2.29

Muhammad Yusnan, Kamasiah, Risman Iye, Karim, Harziko, Riki Bugis. (2020). ALIH KODE DAN CAMPUR KODE PADA NOVEL BADAI MATAHARI ANDALUSIA KARYA HARY ELPARSIA: Transfer code and mix code in Novels Badai Matahari Andalusia Karya Hary ElParsia. Uniqbu Journal of Social Sciences, 1(1), 1-12. https://doi.org/10.47323/ujss.v1i1.3

Nuril Mufidah \& Intan Izha Rohima. (2020). PENGAJARAN KOSA KATA UNTUK MAHASISWA KELAS INTENSIF BAHASA ARAB: Vocabulary Teaching For Arabic Intensive Class. Uniqbu Journal of Social Sciences, 1(1), 13-24. https://doi.org/10.47323/ujss.v1i1.7

Yulismayanti, Y., Harziko, H., \& Irmawati, A. (2020). KEMAMPUAN MENEMUKAN NILAI EDUKATIF DALAM CERPEN JURU MASAK KARYA DAMHURI MUHAMMAD SISWA KELAS X SMA NEGERI 12 BURU: (The Avility to Find Educative Values in Story of Master Teacher Work of Damhuri Muhammad at SMP 12 Buru). Uniqbu Journal of Social Sciences, 1(2), 35-48. https://doi.org/10.47323/ujss.v1i2.23

Hajar, I., Ternate, K., Mukadar, S., AR, N., \& Badu, T. K. (2020). LEARNING STYLE OF AN OUTSTANDING STUDENT IN ENGLISH LEARNING AT SMA NEGERI 1 BURU : (Gaya Belajar Bahasa Inggris Siswa Berprestasi di SMA Negeri 1 Buru). Uniqbu Journal of Social Sciences, 1(2), 78-85.

https://doi.org/10.47323/ujss.v1i2.42 